\title{
Optimizing culture conditions for establishment of hairy root culture of Semecarpus anacardium $\mathbf{L}$.
}

\author{
Bhuban Mohan Panda ${ }^{1,2} \cdot$ Urmil J. Mehta $^{1} \cdot$ Sulekha Hazra $^{1}$
}

Received: 22 September 2016/ Accepted: 7 January 2017/Published online: 11 April 2017

(C) The Author(s) 2017. This article is an open access publication

\begin{abstract}
Semecarpus anacardium L. is a tree species which produces secondary metabolites of medicinal importance. Roots of the plant have been traditionally used in folk medicines. Different strains of Agrobacterium rhizogenes (A4, ATCC15834 and LBA 9402) were used for induction of hairy roots in in vitro grown tissues of the plant. Hairy root initiation was observed after 25-30 days of infection. Optimum transformation frequency of $61 \%$ was achieved on leaf explants with ATCC15834 strain. Infection time of $30 \mathrm{~min}$ resulted in greater transformation frequency compared to 10 and $20 \mathrm{~min}$, respectively. The hairy roots cultured in growth regulator-free semi-solid woody plant medium differentiated into callus. Whole shoots infected with ATCC 15834 were found to produce more transformants upon co-cultivation for $4(65 \%)$ and 5 $(67 \%)$ days. Induction of hairy roots in stem explants infected with ATCC 15834 was lower (52\%) compared to leaves (62\%) after 4 days of co-cultivation. In A4 and LBA9402 strains transformation efficiency was $49 \pm 2.8 \%$ and $36 \pm 5.7 \%$ in shoots after 4 days of co-cultivation. Transformation frequency was higher in ATCC15834 strain, irrespective of explants. The hairy roots of $S$. anacardium elongated slowly upon transfer to half-strength
\end{abstract}

Bhuban Mohan Panda

mbhuban@gmail.com

Urmil J. Mehta

uj.mehta@ncl.res.in

Sulekha Hazra

s.hazra@ncl.res.in

1 Plant Tissue Culture Division, CSIR-National Chemical Laboratory, Pune, India

2 Present Address: Ajeet Seed Ltd, Chitegaon, Paithan, Aurangabad, Maharashtra 431105, India liquid medium. After 3-4 passages in liquid medium slender hairy roots started differentiating which were separated from the original explants. Visible growth of the roots was observed in hormone-free liquid medium after 2-3 months of culturing. Polymerase chain reaction with gene-specific primers from $\operatorname{rol} A, B$ and $C$ genes confirms the positive transformation events.

Keywords Hairy root culture - In vitro culture · Semecarpus anacardium $\cdot$ rol genes · Transformation
Abbreviations
WPM Woody plant medium
PCR Polymerase chain reaction
HRC Hairy root culture
GR Growth regulators
DNA Deoxyribose nucleic acid
YMB Yeast mannitol broth

\section{Introduction}

Plants have been tapped as "chemical factories" for their ability to produce phytochemicals of industrial and pharmaceutical importance from simple building blocks. The major drawback of extracting phytochemicals from normal plant tissue is that their growth and yield are significantly impacted due to environmental factors. The complex extraction procedure itself is detrimental to plant survival (Ono and Tian 2011). Semecarpus anacardium (Anacardiaceae), commonly known as marking nut tree, is used as an herbal drug in Ayurvedic and Unani medicines for being caustic, astringent, antirheumatic, vesicant and for being 
used to treat anorexia, cough, asthma, indigestion, ulcer, piles and various neurological diseases (Nadkarni 1976). These medicinal properties of $S$. anacardium $\mathrm{L}$. are attributable to production of secondary metabolites (Raut et al. 2007). The roots of this plant have been used in folk medicine as anti-fertility agent for women. There is no report on chemical characteristics of the compounds present in roots.

Various aspects and applications of hairy root cultures (HRCs), include phytochemicals, recombinant protein production, phytoremediation, molecular breeding and crop improvement, introduction of desirable foreign genes, rhizosphere physiology and biochemistry, metabolic engineering, bioreactor design and general overviews of the system (Ono and Tian 2011). Nowadays, HRCs receive more attention as biological matrices for producing valuable metabolites as they have several attractive features, including high genetic stability and relatively fast growth rates. Harvesting the roots for medicinal and chemical uses is destructive for the plants and hence there has been increasing interest in developing hairy root cultures from several medicinal plant species (Zhou et al. 2011).

Initiation and establishment of HRCs in S. anacardium could lead to development of an independent in vitro system. This can be used to study the production and identification of chemical compounds in controlled environments. The present investigation was conducted to optimize conditions for establishment of hairy root culture of $S$. anacardium. These experiments reports, establishment of hairy root culture using A. rhizogenes ATCC15834 from leaf explants. Virulence of different strains (ATCC 15834, A4 and LBA9402) and susceptibility of different explants (leaf, stem (shoot without leaves) and shoots) were optimized. Compatibility of bacterial strain and explant type was discussed. Finally, confirmations of transformation by PCR using rol specific primers were described.

\section{Materials and methods}

\section{Bacterial strains}

Three wild-type agropine strains of A. rhizogenes (ATCC15834, A4 and LBA9402) were used for transformation. A. rhizogenes ATCC15834 were kindly provided by Prof. Sujata Bhargava (Department of Botany, University of Pune) for preliminary investigation of transformation procedure. Strains A4 and LBA9402 were obtained from Prof. Sumita Jha (Center of Advanced Studies in Cell and Chromosome Research, Department of Botany, University of Calcutta, Kolkata).

\section{Bacterial media and growth}

Yeast mannitol broth (YMB) medium was used for bacterial culture. Fresh bacterial culture was initiated from glycerol stock. The bacteria were streaked on nutrient YMB agar $(15 \mathrm{~g} / \mathrm{l})$ medium and incubated for $48 \mathrm{~h}$ at $27^{\circ} \mathrm{C}$. Single colony of the A. rhizogenes was picked up and inoculated in $10 \mathrm{ml}$ of YMB nutrient broth. The culture was incubated at $27^{\circ} \mathrm{C}$ on rotary shaker at $120-130 \mathrm{rpm}$. Bacterial culture with approximate optical density (1.0) at $600 \mathrm{~nm}$ was used for infecting different explants of $S$. anacardium.

\section{Plant material}

Tissues from seedling-derived in vitro shoot cultures of $S$. anacardium were used as explants (Panda and Hazra 2010). Leaves, stems and shoots were isolated from axenic cultures maintained in charcoal incorporated WPM medium (Lloyd and McCown 1980).

\section{Infection and co-cultivation of explants}

Isolated leaves, stems (shoots without leaves) and whole shoots were infected with different strains of A. rhizogenes ATCC15834, A4 and LBA9402. These explants were transferred aseptically to $90 \mathrm{~mm}$ Petri dishes containing $20 \mathrm{ml}$ of bacterial suspension. For experimental control the bacterial suspension was substituted with YMB medium. All the explants were pricked with the help of sterile hypodermic syringe needle, Dispovan (Hindustan Syringes and Medical Devices Ltd, Haryana, India). In the first experiment A. rhizogenes ATCC15834 was used to optimize duration of infection and co-cultivation period with leaf explants. In the second experiment, A. rhizogenes A4 and LBA9402 strains were tested along with A. rhizogenes ATCC15834 in conjunction with different explants including leaves, stems and shoots. The wounded explants were removed from bacterial suspension, blotted dry on filter paper and cultured on half-strength semisolid WPM basal medium in Petri dishes. The cultures were co-cultivated in light for different periods of time duration ranging from 1 to 7 days. Explants from various time periods of cocultivation were washed in antibiotic solution of cefotaxime (Alkem, India) $(400 \mathrm{mg} / \mathrm{l})$ to eliminate remaining A. rhizogenes. The explants were transferred to halfstrength WPM basal medium containing $400 \mathrm{mg} / \mathrm{l}$ cefotaxime after drying on filter paper. Explants from the control cultures were also treated similarly. Ten to fifteen explants were inoculated in each plate with 3-4 plates per replicate. All experiments were done in triplicate. Observations were recorded after 8 weeks of culture. Concentration of cefotaxime in semi-solid media was halved each 
week and finally, cultures free of $A$. rhizogenes were transferred to half-strength WPM without antibiotics. Explants with single root or root cluster were noted for transformation. The frequency of infection was determined. DNA isolated from untransformed roots that were induced from shoot cultures served as negative control.

All cultures were incubated at $25 \pm 2{ }^{\circ} \mathrm{C}$ temperature in $16 \mathrm{~h}$ photoperiod under diffuse cool white fluorescent lights $\left(50 \mu \mathrm{mol} / \mathrm{m}^{2} / \mathrm{s}\right)$. The observed data were subjected to Analysis of Variance (ANOVA). Graphs were plotted using Origin 6.1 software.

\section{DNA isolation}

Genomic deoxyribose nucleic acid (DNA) was extracted from the putatively transformed and untransformed roots (from shoot cultures) following the protocol of Khanuja et al. (1999).

\section{Plasmid DNA isolation}

Plasmid DNA from the A. rhizogenes strains was isolated using standard alkaline lysis method (Sambrook et al. 1998). Quantitative and qualitative estimation was also done with spectrophotometer. For visual estimation of quantity, plasmid DNA was loaded in $0.8 \%$ agarose gel with $\lambda$ DNA as standard.

\section{Primers used for screening of rol genes}

Transformants were screened for the presence of $\operatorname{rol} A, B$ and $C$ genes using the sequence specific primers. The primers were custom synthesized from MWG-Biotech, Bangalore, India.

For rol $A$ gene: For-5'-CAGAATGGAATTAGCCG GACTAA-3'

Rev-5'-CGTATTAATCCCGTAGGTTTGTTT-3'

For rol $B$ gene: For-5'-ATGGATCCCAAATTGC TATTCCCCCACGA-3'

Rev-5'-TTAGGCTTCTTTCATTCGGTTTACTG-

CAGC-3'

For rol $C$ gene: For-5'-CATTAGCCGATTGCA AACTTG-3'

Rev-5'-ATGGCTGAAGACGACCTG-3'

\section{PCR condition}

The PCR reactions were carried out in $25 \mu \mathrm{l}$ volume and consist of $40 \mathrm{ng}$ of DNA, $10 \mathrm{pm} / \mu \mathrm{l}$ primer, $200 \mathrm{mM} \mathrm{dNTP}$, $1 \mathrm{U}$ of Taq DNA polymerase, $1 \times$ PCR buffer and $1.5 \mathrm{mM}$ $\mathrm{MgCl}_{2}$. All the PCR components were from Genei, Bangalore. Amplification of DNA was performed in a thermal cycler (Veriti thermal cycler, Applied Biosystems) using the following sequence: initial denaturation at $94{ }^{\circ} \mathrm{C}$ for $5 \mathrm{~min}$, followed by 35 cycles of $94{ }^{\circ} \mathrm{C}$ for $1 \mathrm{~min}$, annealing $52.5{ }^{\circ} \mathrm{C}$ (rolB gene) $/ 62{ }^{\circ} \mathrm{C}$ (rolA and $C$ gene) for $1.5 \mathrm{~min}$ and $72{ }^{\circ} \mathrm{C}$ for $2 \mathrm{~min}$ followed by final extension at $72{ }^{\circ} \mathrm{C}$ for $10 \mathrm{~min}$. The amplification products were visualized on $1.5 \% \mathrm{w} / \mathrm{v}$ agarose gel stained with ethidium bromide.

\section{Results and discussion}

Factors that influence successful transformation in plant tissue and hairy root induction include genotype, species, age, type of plant tissue (Sevon et al. 2002), type of Agrobacterium strain, density of the bacterial suspension (Park and Facchini 2000), time duration of infection and media composition (Nourozi et al. 2016). A number of chemicals may also promote these processes, e.g., acetosyringone (Joubert et al. 2002).

\section{Infection of leaf explants with $A$. rhizogenes ATCC15834}

Optimum transformation frequency of $61 \%$ was noted in explants of $S$. anacardium L. infected for $30 \mathrm{~min}$ in the bacterial suspension (Table 1). Explants with $10 \mathrm{~min}$ of infection did not show any transformation except on the 4th day of co-cultivation. Varying percentages of transformation were observed within 20 min of infection (Table 1). Researchers have reported effect of infection time on transformation frequency using $A$. rhizogenes which depends on plant species. Five minutes of infection to wounded explants was effective in inducing hairy roots in Datura tatula L. (Peng et al. 2008), Papaver bracteatum Lindl. (Rostampour et al. 2009), Echinacea sp. (Romero et al. 2009) in Linum mucronatum (Samadi et al. 2012) and in Agastache foeniculum (Nourozi et al. 2016), whereas in Silybum marianum (Rahnama et al. 2008) and in Fagopyrum tataricum (Thwe et al. 2016), 10 min of infection was optimum. The infection time was $20 \mathrm{~min}$ in Artemisia annua (Giri et al. 2001) and in Portulaca oleracea (Moghadam et al. 2014). In glycine $\max 45$ min of infection was required (Liu et al. 2008) to get successful transformation.

In $S$. anacardium varied transformation frequency was observed when the leaf explants were co-cultivated for different durations. Optimum transformation was achieved in explants kept for 4 days of co-cultivation on growth regulator-free medium (Table 1). In Rehmannia glutinosa (Hwang 2009) the co-cultivation period was 1 day to achieve $46.7 \%$ transformation. Two days of co-cultivation was effective to obtain $59 \%$ of transformants in Saponaria vaccaria L. (Schmidt et al. 2007), 60\% in L. mucronatum 
Table 1 Effect of infection time on transformation frequency (\%) of A. rhizogenes ATCC15834 with leaves as explants

\begin{tabular}{|c|c|c|c|}
\hline \multirow[t]{3}{*}{ Days of co-cultivation } & \multicolumn{3}{|c|}{ Transformation frequency $(\%)$ (mean $\pm \mathrm{SD})$} \\
\hline & \multicolumn{3}{|c|}{ Time duration of infection } \\
\hline & $10 \mathrm{~min}$ & $20 \mathrm{~min}$ & $30 \min$ \\
\hline 1 & $00 \pm 00(135)$ & $00(115)$ & $00 \pm 00(130)$ \\
\hline 2 & $00 \pm 00(125)$ & $23 \pm 1.4(106)$ & $35 \pm 2.12(140)$ \\
\hline 3 & $00 \pm 00(98)$ & $28 \pm 4.12(106)$ & $49 \pm 3.5(128)$ \\
\hline 4 & $7 \pm 00(122)$ & $39 \pm 2.5(123)$ & $61 \pm 2.8(110)$ \\
\hline 5 & $00 \pm 00(140)$ & $25 \pm 2.8(90)$ & $53 \pm 2.12(95)$ \\
\hline 6 & $00 \pm 00(102)$ & $15 \pm 2.12(145)$ & $42 \pm 4.2(145)$ \\
\hline 7 & $00 \pm 00(110)$ & $7 \pm 1.4(120)$ & $29 \pm 2.12(116)$ \\
\hline ANOVA & - & Sig $1 \%$ & Sig $1 \%$ \\
\hline
\end{tabular}

Figures in parenthesis () indicates number of replicates

(Samadi et al. 2012), and 75\% in Arachis hypogaea L. (Kim et al. 2008). S. marianum (Rahnama et al. 2008) Tylophora indica (Chaudhuri et al. 2005) and Gmelina arborea Roxb (Dhakulkar et al. 2005) needed 3 days of cocultivation to get optimum transformation frequency of 30 , 60 and 32\%, respectively, using Agrobacterium rhizogenes strains. Optimum transformation frequency of $45 \%$ was achieved in Chonemorpha fragrans (Moon) Alston, after 7 days of co cultivation (Kedari and Malpathak 2014). In the present study there was no root formation in control leaf explants treated with YMB medium (Fig. 1a). However, in Semecarpus the leaf explants co-cultivated with A. rhizogenes for 3-4 days showed successful root induction after 25-30 days of culture in antibiotic-supplemented medium over three passages of 7 days each (Fig. 1b). Root induction was observed frequently in Agrobacterium-infected leaves of Semecarpus injured along the midrib. Differentiation of roots from the wounded sites in midrib region of leaf was associated with callusing (Fig. 1c). Callusing from the wounded sites of seedling explants of California poppy (Park and Facchini 2000) and nodes/internodal explants in $T$. indica (Chaudhuri et al. 2005) in response to Agrobacterium had been reported. Hairy root development was confined to wounded site of explants in Rubina tinctorum (Ercan et al. 1999), Papaver somniferum (Park and Facchini 2000) and in A. hypogaea (Kim et al. 2008). Roots with hairy structures elongated and callusing at the base of the roots were observed in some of the cultures (Fig. 1d). It has been reported that cell division in the host target explants tissue is a prerequisite for successful Agrobacterium transformation (Binns and Thomashow 1988). Thin slender roots with root hairs developed from the clusters of roots on culturing in GR-free halfstrength WPM (Fig. 1e). Transformed roots grew in cluster from the midrib region of the leaves on culturing in half- strength basal medium without antibiotics for 12 weeks (Fig. 1f).

\section{Virulence of different Agrobacterium strains (A4, ATCC15834 and LBA9402) and susceptibility of explants (leaf, stem and shoot)}

Experiments were extended to determine the optimum cocultivation period and efficacy of different bacterial strains to induce hairy roots in different explants. Varying root induction with different period of co-cultivation was observed in leaf explants infected with A. rhizogenes strains. In leaf explants of $S$. anacardium optimum rooting frequency was $62 \pm 2.12 \%$, infected with strain ATCC15834 and co-cultivated for 4 days was observed. The results concur with earlier observation of transformation in leaves. Strains A4 and LBA9402 induce rooting in $59 \pm 4.94$ and $42 \pm 12.02 \%$ leaf explants, respectively, during the same co-cultivation period (Table 2).

Induction of hairy roots in stem explants was (52\%) compared to leaves $(62 \%)$ after 4 days of co-cultivation. Rooting frequency increased to $60 \pm 9 \%$ in stem explants after 5 days of co-cultivation. Like leaf explants, stem explants also exhibited higher rooting as well as the transformation frequency when infected with strain ATCC15834. Transformed roots originated in cluster from stem explants cultured in half-strength WPM without GR (Fig. 1g). These roots grew slowly and covered the surface of solid media in petriplates. Optimum hairy root induction of $67 \pm 2.3 \%$ in shoot explants was noted in shoot explants cocultivated for 5 days with A.Rhizogenes ATCC 15834. whereas $65 \%$ of root initiation was observed in 4 days cocultivations. Transformation frequency with A4 and LBA9402 strains was $49 \pm 2.8$ and $36 \pm 5.7 \%$, respectively, in shoots co-cultivated for 4 days. A. rhizogenes 

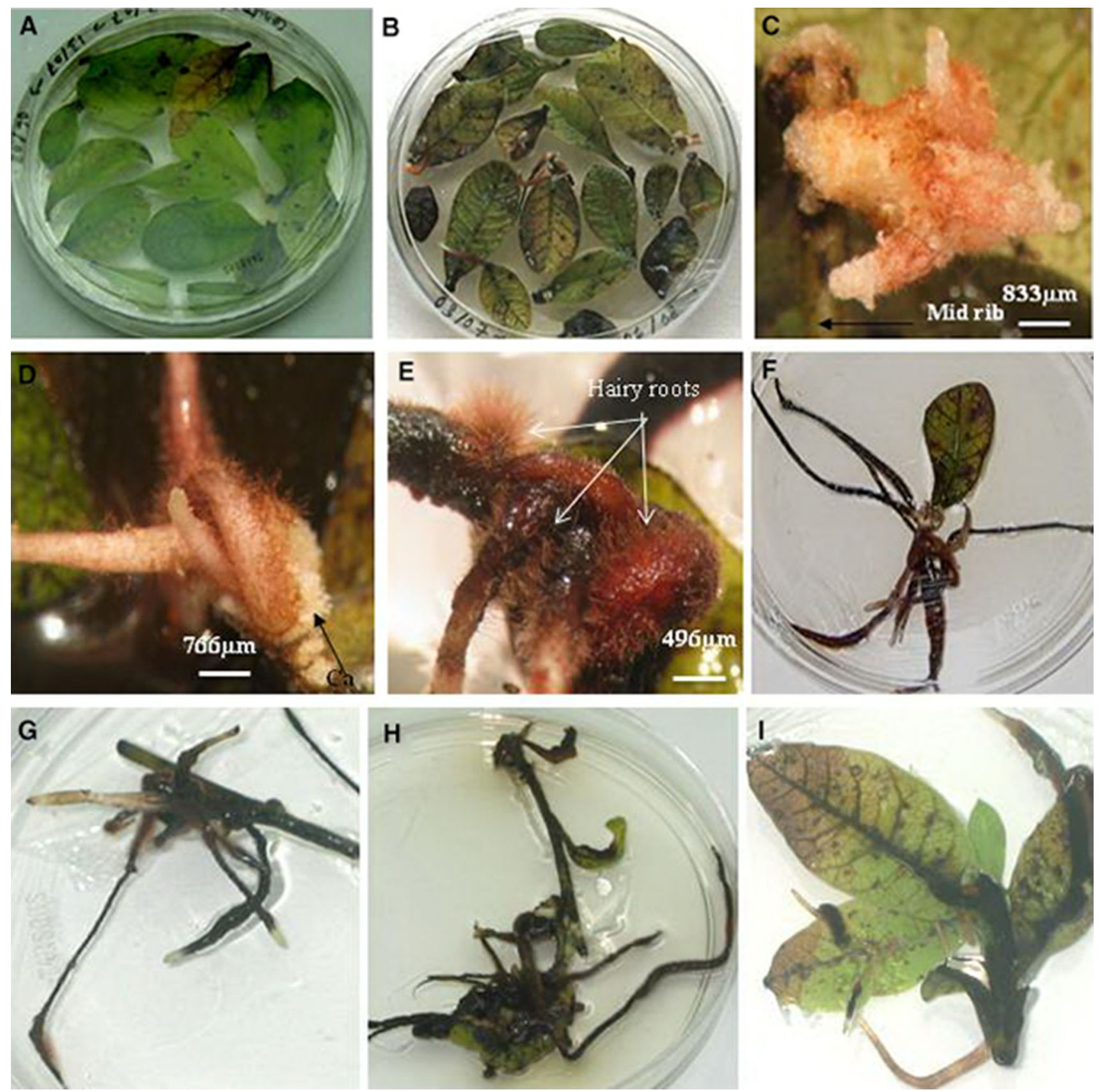

Fig. 1 Induction of hairy roots in different explants. a Control leaf explants in half-strength WPM medium without any root development after 8 weeks of culturing in antibiotic-incorporated medium. b Induction of root in leaves infected with A. rhizogenes after 3-4 weeks of culturing in half-strength WPM medium containing antibiotics. c Initiation of hairy root-like structure originating from the mid rib region of leaf explants in half-strength WPM medium containing antibiotics. d Cluster of roots with fine root hairs arising from the leaf explants in half-strength WPM medium containing antibiotic; the base of the roots are associated with callus. e Thin slender roots with

strain ATCC15834 was found to be more virulent in all the three types of explants. Strain ATCC15834 was more potent in infecting cotyledon explants of Rubia tinctorum root hairs developed from the clusters of roots on culturing in GR-free half-strength WPM medium. f Cluster of hairy roots showing growth and elongation from leaf explants infected with A. rhizogenes cultured in half-strength WPM medium. g Initiation and growth of hairy roots from stem explants cultured in half-strength WPM medium. h Hairy roots in stem explants originate mostly from leaves attached to shoot explants infected with A. rhizogenes in half-strength WPM medium. i Emergence of hairy roots from the mid rib region of leaf explants attached to shoot

(Ercan et al. 1999) in comparison to strains 2628, R1000 and 9365 . This strain was one of the potent $A$. rhizogenes for transformation in Capsicum frutescens (Setamam et al. 
Table 2 Effects of co-cultivation duration and bacterial strains on transformation frequency (\%) of different explants

\begin{tabular}{|c|c|c|c|c|c|c|c|}
\hline \multirow[t]{3}{*}{ Bacterial strains } & \multicolumn{7}{|c|}{ Transformation frequency $(\%)($ mean \pm SD) } \\
\hline & \multicolumn{7}{|c|}{ Days of co-cultivation } \\
\hline & 1 & 2 & 3 & 4 & 5 & 6 & 7 \\
\hline \multicolumn{8}{|l|}{ Leaf explants } \\
\hline Control & $00 \pm 00(96)$ & $00 \pm 00(112)$ & $00 \pm 00(110)$ & $00 \pm 00(133)$ & $00 \pm 00(123)$ & $00 \pm 00(98)$ & $00 \pm 00(129)$ \\
\hline A4 & $00 \pm 00(98)$ & $32.5 \pm 11(120)$ & $47 \pm 8.9(123)$ & $58.5 \pm 5(128)$ & $46.5 \pm 9(112)$ & $30 \pm 4.24(120)$ & $27 \pm 4.3(142)$ \\
\hline ATCC15834 & $00 \pm 00(96)$ & $30 \pm 4(116)$ & $51.5 \pm 2.2(148)$ & $61.5 \pm 2(132)$ & $53 \pm 2(134)$ & $40 \pm 2.82(143)$ & $28 \pm 2.8(114)$ \\
\hline LBA9402 & $00 \pm 00(98)$ & $31 \pm 11(125)$ & $41.5 \pm 11(120)$ & $41.5 \pm 12(147)$ & $35.5 \pm 4(125)$ & $31 \pm 9.19(150)$ & $23 \pm 9.89(114)$ \\
\hline ANOVA & & NS & Sig $5 \%$ & Sig $1 \%$ & Sig $1 \%$ & Sig $1 \%$ & Sig $1 \%$ \\
\hline \multicolumn{8}{|l|}{ Stem explants } \\
\hline Control & $00 \pm 00(96)$ & $00 \pm 00(106)$ & $00 \pm 00(112)$ & $00 \pm 00(132)$ & $00 \pm 00(95)$ & $00 \pm 00(96)$ & $00 \pm 00(124)$ \\
\hline A4 & $00 \pm 00(90)$ & $31 \pm 18(103)$ & $32.5 \pm 11(113)$ & $45 \pm 7(134)$ & $52 \pm 3(96)$ & $40 \pm 3(95)$ & $39 \pm 1.4(123)$ \\
\hline ATCC15834 & $00 \pm 00(93)$ & $35 \pm 3(123)$ & $43.5 \pm 4(120)$ & $52 \pm 3(122)$ & $60 \pm 9(103)$ & $44 \pm 3(116)$ & $37 \pm 5.6(143)$ \\
\hline LBA9402 & $00 \pm 00(92)$ & $32 \pm 10(121)$ & $29.5 \pm 12(94)$ & $39 \pm 2(110)$ & $42 \pm 1(107)$ & $35 \pm 4(112)$ & $29 \pm 8.4(134)$ \\
\hline ANOVA & & NS & Sig $5 \%$ & Sig $1 \%$ & Sig $1 \%$ & Sig $1 \%$ & Sig $1 \%$ \\
\hline \multicolumn{8}{|l|}{ Shoot explants } \\
\hline Control & $00 \pm 00(112)$ & $00 \pm 00(116)$ & $00 \pm 00(128)$ & $00 \pm 00(134)$ & $00 \pm 00(102)$ & $00 \pm 00(122)$ & $00 \pm 00$ \\
\hline A4 & $00 \pm 00(122)$ & $20 \pm 10(110)$ & $37 \pm 28.8$ & $49 \pm 3(121)$ & $39 \pm 11(112)$ & $41 \pm 17(127)$ & $44 \pm 3.6(98)$ \\
\hline ATCC15834 & $00 \pm 00(124)$ & $32 \pm 3(123)$ & $43 \pm 15.3$ & $65 \pm 10(118)$ & $67 \pm 3(134)$ & $63 \pm 12(146)$ & $58 \pm 8(95)$ \\
\hline LBA9402 & $00 \pm 00$ & $17 \pm 8(116)$ & $27 \pm 15.3$ & $36 \pm 5.7(118)$ & $33 \pm 7.6(126)$ & $32 \pm 8(133)$ & $27 \pm 12(104)$ \\
\hline ANOVA & - & Sig $1 \%$ & Sig $1 \%$ & Sig $1 \%$ & Sig $1 \%$ & Sig $1 \%$ & Sig 5\% \\
\hline
\end{tabular}

Figure in parenthesis () indicates number of replicates

2014). Roots in clusters (Fig. 1h) arose from the wounded sites of intact leaves of shoots. The root induction location was mainly concentrated in the midrib region of leaves (Fig. 1i). Rooting from the veins of leaf in Pueraria phaseoloides infected with A. rhizogenes ATCC15834 was noted (Shi and Kintzios 2003).

To summarize the data generated in this experiments, $A$. rhizogenes ATCC15834 is the best strainand shoots are the most suitable explants. The optimum transformation frequency in shoot explants of $S$. anacardium may be ascribed to the presence of intact leaves in addition to stem. Shoots are the explants of choice for hairy root induction using A. rhizogenes in apple rootstock Jork 9 (Pawlicki-Jullian et al. 2002), P. bracteatum Lindl. (Rostampour et al. 2009) and in T. indica (Chaudhuri et al. 2005). Virulence or infectivity of Agrobacterium strains varies among plant hosts and explant types (Hobbs et al. 1989; Bush and Pueppke 1991; Baranski et al. 2006). High frequency of hairy root induction in leaf explants of Pelargonium sp. and Psoralea corylifolia compared to internodes and petioles was observed by Saxena et al. 2007 and Rajkumar and Murugesan, 2014, respectively.

Transformation efficiency in plant species can diverge between different bacterial strains (Godwin et al. 1991; Hu and Alfermann 1993). Optimum hairy root initiation was reported in shoot tips of A. апnиа infected with A. rhizogenes
Fig. 2 Comparison of hairy root induction in different explants, callusing of hairy roots in solid medium and hairy root culture in liquid medium. a Comparison of different $A$. rhizogenes strain and explant type after 4 days of co-cultivation periods on transformation frequency of $S$. anacardium. b, c Hairy roots dedifferentiated into callus during culturing after limited growth in semi-solid half-strength WPM medium. d Hairy root culture in liquid medium, the original leaf explant was still attached, with dedifferentiation of the roots into callus. e Clump of hairy roots cultured in liquid medium, the medium become brown due to leaching of phenolics compound

LBA9402 than strain A4, ATCC15834, 9365 and 9340 (Giri et al. 2001). Similarly, in leaf explants of Saponaria vaccaria L., strain LBA9402 was found to be more potent than A. rhizogenes ATCC15834 for infection (Schmidt et al. 2007). A. rhizogenes A4 is reportedly most potent for dicotyledonous plants (Kuzovkina and Schneider 2006). In leaf explants of Pelargonium sp., 100\% transformation frequency was reported with strain A4 (Saxena et al. 2007).

In $S$. anacardium $\mathrm{HRCs}$, root thickening and dedifferentiation into callus were observed on further culturing in semi-solid medium (Fig. 2b, c). Shorter and thicker root development has been observed in apple rootstock jork9 with A. rhizogenes ATCC15834 (Pawlicki-Jullian et al. 2002). The hairy roots of $S$. anacardium elongates on transferring to half-strength liquid medium. But the elongation rate was very slow in thicker roots (data not shown). 

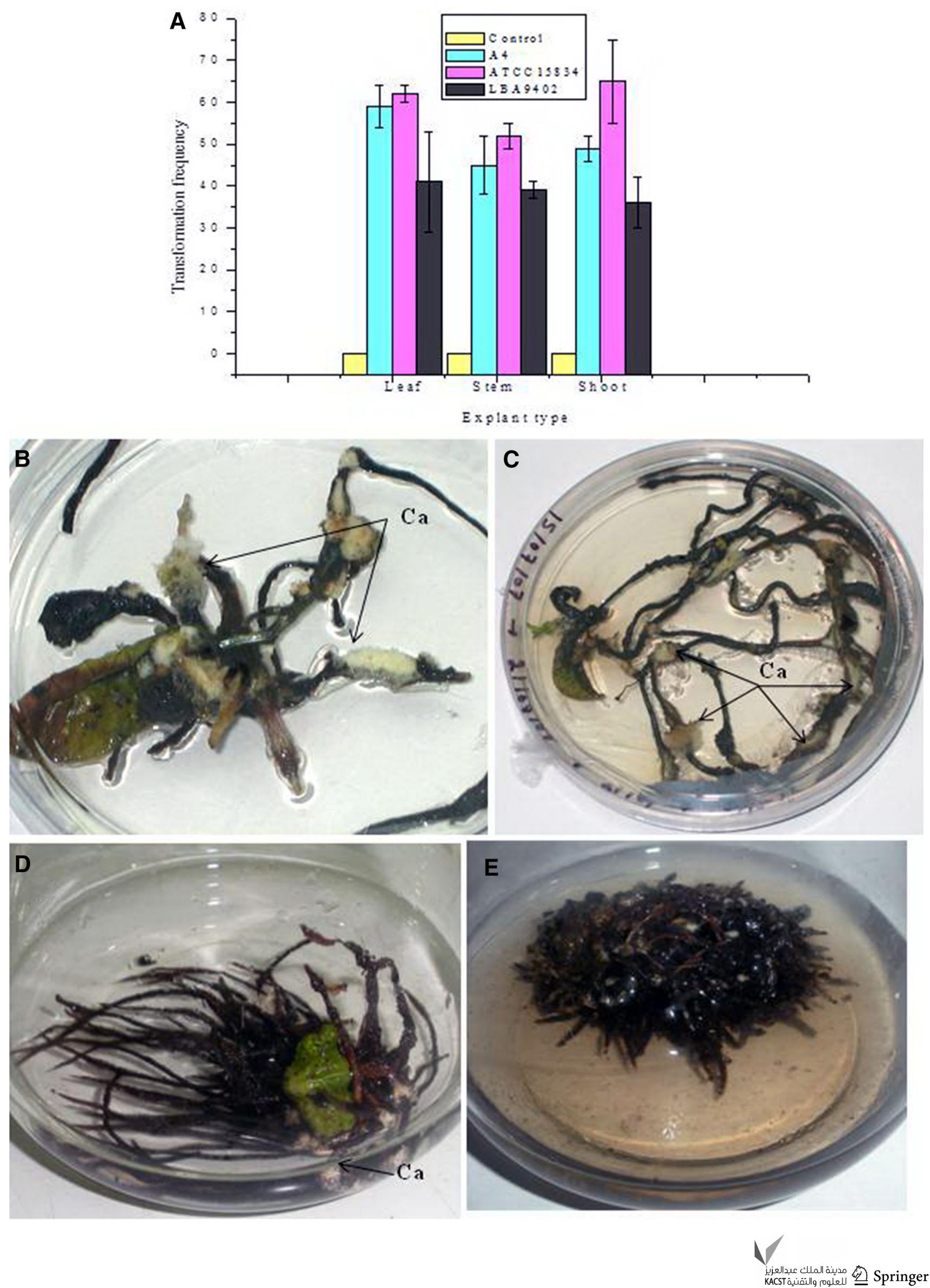
After 3-4 passages in liquid medium thin hairy roots started differentiating slowly which were separated from the original explants. Visible growth of the roots was observed in liquid medium after 2-3 months of culturing (Fig. 2d, e). The slow growth of HRCs in $S$. anacardium could be due to the presence of excess growth inhibitory phenolics in the culture or due to slow growth habit of tree sp. in vitro.

The browning of the culture medium was indicative of leaching of phenolics (Fig. 2c, e). Further biochemical studies are required to reveal the nature of phenolics compounds. Callus formation from the roots in liquid medium was noted, and similar differentiation of the roots was already observed in semisolid medium. Callusing in hairy roots cultured in GR-free medium was reported in $D$. tatula L. (Peng et al. 2008) and was assigned due to high capacity of the tissue to dedifferentiate resulting in callus formation. Callus formation was also observed in the hairy roots of Bacopa monnieri induced by $A$. rhizogenes LBA9402 (Majumdar et al. 2011). Large numbers of $A$. rhizogenes-mediated hairy root lines were produced in $S$. anacardium L. but only very few of those gave rise to HRCs. This could be due to the different sites of insertion of T-DNA as well as the copy number of transgenes. In addition, deletions and/or duplications of T-DNA sequences or target site sequences may also lead to variation in the hairy root clones (Dhakulkar et al. 2005).

\section{Confirmation of transgenic status}

However, due to the plasticity of the plant cells roots could be induced in explants in condition other than that of transformation. Therefore, efforts were made to confirm the presence of rol genes using PCR. Confirmation of transgenic status of the tissue was done with PCR amplification of the DNA isolated from the hairy roots using forward and reverse primers of rol genes (rolA, rolB and rolC). Plasmids from $A$. rhizogenes served as the positive control, and DNA from the non-transformed roots of shoot culture served as the negative control. All transformants (infected with different strains) showed the presence of the rolA (300 bp) (Fig. 3a), rolB (780 bp) (Fig. 3b) and rolC (590 bp) (Fig. 3c) in DNA-amplified product, confirming the transgenic nature of the hairy root lines.

\section{Conclusion}

In the present investigation hairy root cultures were established from an important medicinal woody tree $S$. anacardium. Induction of hairy root occurs at frequency of
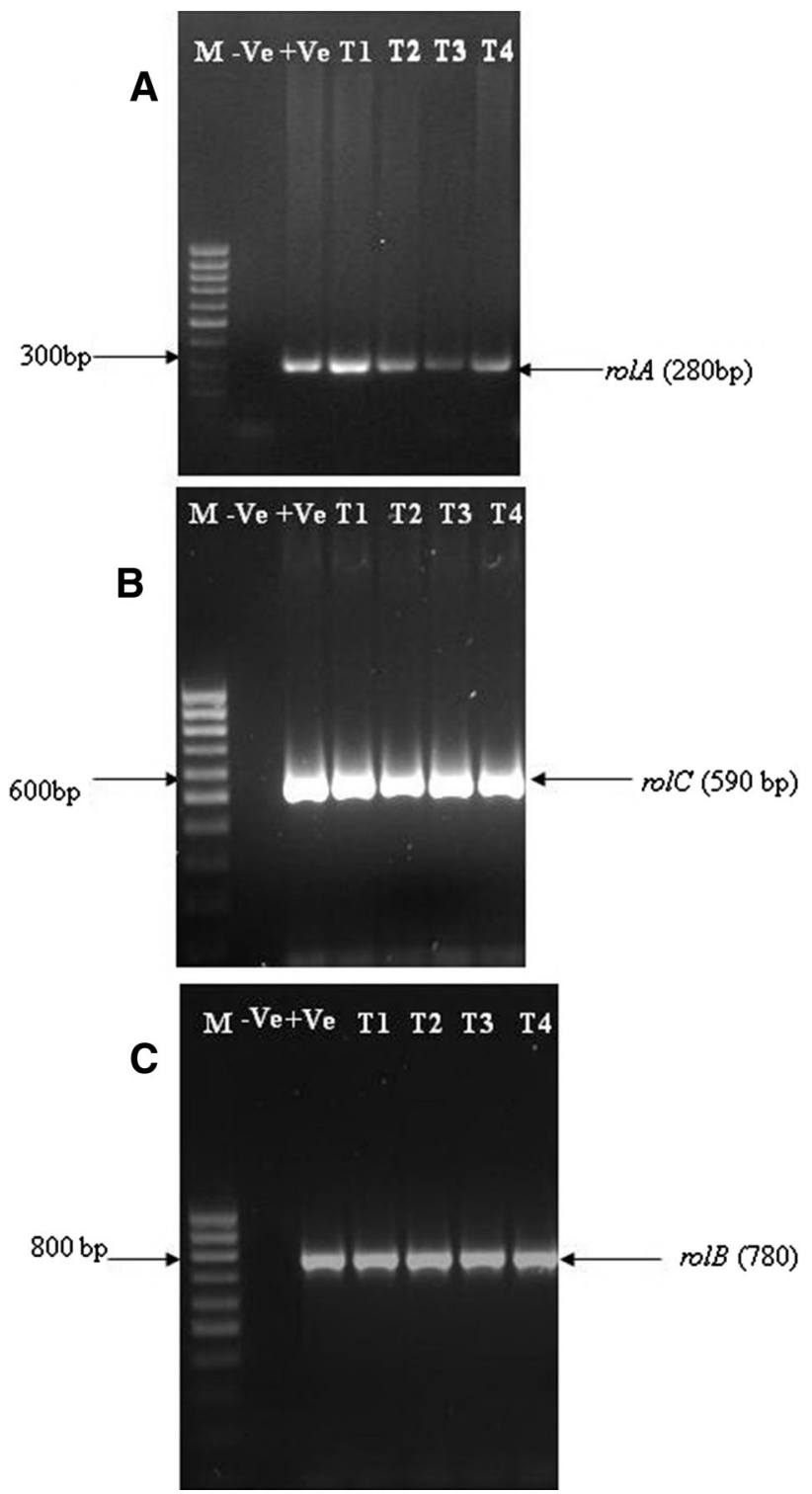

Fig. 3 Confirmation of transformation by PCR. a PCR amplification of $280 \mathrm{bp}$ fragment of the rolA gene. Lane 1 molecular weight marker (100 bp ladder); lane 2 DNA from non-transformed roots (negative control); lane 3 A. rhizogenes plasmid DNA (positive control); lane 4 sample 1; lane 5 sample 2; lane 6 sample 3; lane 7 sample 4. Samples $1,2,3$ and 4 were DNA of transformed roots obtained after $A$. rhizogenes infection. b PCR amplification of $590 \mathrm{bp}$ fragment of the rolC gene. Lane 1 molecular weight marker (100 bp ladder); lane 2 DNA from non-transformed roots (negative control); lane 3 A. rhizogenes plasmid DNA (positive control); lane 4 sample 1; lane 5 sample 2; lane 6 sample 3; lane 7 sample 4. Samples 1, 2, 3 and 4 were DNA of transformed roots obtained after A. rhizogenes infection. c PCR amplification of $780 \mathrm{bp}$ fragment of the rolB gene. Lane 1 molecular weight marker (100 bp ladder); lane 2 DNA from non-transformed roots (negative control); lane 3 A. rhizogenes plasmid DNA (positive control); lane 4 sample 1; lane 5 sample 2; lane 6 sample 3; lane 7 sample 4. Samples 1, 2, 3 and 4 were DNA of transformed roots obtained after A. rhizogenes infection 
67 and $62 \%$ in shoot and leaf explants, respectively. There was a significant difference in hairy root induction with respect to the type of explants and bacterial strains used. Shoot was found to be the explant of choice for hairy root induction compared to stem and leaves. Among the bacterial strains tested ATCC15834 was found to be the most virulent than A4 and LBA9402. These are some of the preliminary findings regarding hairy root culture for $S$. anacardium. Further research needs to be done for isolation, identification and scaling up of novel secondary metabolites in hairy root cultures.

Acknowledgements Bhuban Mohan Panda is thankful to CSIR, India, for the junior and senior research fellowship. The authors are thankful to Prof. Sujata Bhargava and Prof. Sumita Jha for kindly providing the bacterial strains for research. Encouragement from Dr. S. K. Rawal (DOR, Ajeet Seed Ltd.) and Dr. S. N. Mukherjee for publishing the manuscript is highly appreciated. Thanks are also due for Dr. V. S. S. Prasad for his constant help.

\section{Compliance with ethical standards}

Conflicts of interest The authors declare no conflict of interest.

Open Access This article is distributed under the terms of the Creative Commons Attribution 4.0 International License (http:// creativecommons.org/licenses/by/4.0/), which permits unrestricted use, distribution, and reproduction in any medium, provided you give appropriate credit to the original author(s) and the source, provide a link to the Creative Commons license, and indicate if changes were made.

\section{References}

Baranski B, Klocke E, Schumann G (2006) Green fluorescent protein as an efficient selection marker for Agrobacterium rhizogenes mediated carrot transformation. Plant Cell Rep 25:190-197

Binns AN, Thomashow MF (1988) Cell biology of Agrobacterium infection and transformation of plants. Annu Rev Microbiol 42:575-606

Bush AL, Pueppke SG (1991) Cultivar-strain specificity between Chrysanthemum morifolium and Agrobacterium tumefaciens. Physiol Mol Plant Pathol 39:309-323

Chaudhuri KN, Ghosh B, Tepfer D, Jha S (2005) Genetic transformation of Tylophora indica with Agrobacterium rhizogenes A4: growth and tylophorine productivity in different transformed root clones. Plant Cell Rep 24:25-35

Dhakulkar S, Ganapathi TR, Bhargava S, Bapat VA (2005) Induction of hairy roots in Gmelina arborea Roxb and production of verbascoside in hairy roots. Plant Sci 169:812-818

Ercan AG, Taskin KM, Turgut K, Yuce S (1999) Agrobacterium rhizogenes mediated hairy root formation in some Rubia tinctorum L. populations grown in Turkey. Tr J Bot 23:373-377

Giri A, Ravindra ST, Dhingra V, Narasu ML (2001) Influence of different strains of Agrobacterium rhizogenes on induction of hairy roots and artemisin production in Artemisia annua. Curr Sci 81:378-382

Godwin I, Todd G, Ford-Lloyd B, Newbury HJ (1991) The effects of acetosyringone and $\mathrm{pH}$ on Agrobacterium-mediated transformation vary according to plant species. Plant Cell Rep 9:671-675
Hobbs SLA, Jackson JA, Mahon JD (1989) Specificity of strain and genotype in the susceptibility of pea to Agrobacterium tumefaciens. Plant Cell Rep 8:55-58

Hu ZB, Alfermann AW (1993) Diterpenoid production in hairy root cultures of Salvia miltiorrhiza. Phytochemistry 32:699-703

Hwang S (2009) Catapol production in Chinese foxglove (Rehmannia glutinosa Libos.) hairy roots transformed with Agrobacterium rhizogenes ATCC15834. Methods Mol Biol 547:263-273

Joubert P, Beaupere D, Lelievre P, Wadouachi A, Sangwan RS, Sangwan-Norreel BS (2002) Effect of phenolic compounds on Agrobacterium vir genes and gene transfer induction-a plausible molecular mechanism of phenol binding protein activation. Plant Sci 162:733-743

Kedari P, Malpathak NP (2014) Hairy root cultures of Chonemorpha fragrans (Moon) Alston.: a potential plant for camptothecin production. Indian J Biotechnol 13(2):231-235

Khanuja SPS, Shasany AK, Darokar MP, Kumar S (1999) Rapid isolation of DNA from dry and fresh samples of plants producing large amounts of secondary metabolites and essential oils. Plant Mol Biol Rep 17:1-7

Kim JS, Lee YS, Park S (2008) Resveratrol production in hairy root culture of peanut, Arachis hypogaea L. transformed with different Agrobacterium rhizogenes strains. Afr J Biotechnol 7(20):3788-3790

Kuzovkina IN, Schneider B (2006) Genetically transformed hairy root cultures-regeneration, properties and application in plant science. Prog Bot 67(3):275-314. doi:10.1007/3-540-27998-9_ 13

Liu SJ, Wei ZM, Huang JQ (2008) The effect of co-cultivation and selection parameters on Agrobacterium-mediated transformation of Chinese soybean varieties. Plant Cell Rep 27:489-498

Lloyd G, McCown B (1980) Commercially feasible micropropagation of mountain laurel, Kalmia latifolia. Intl Plant Prop Soc Proc 30:421-427

Majumdar S, Garai S, Jha S (2011) Genetic transformation of Bacopa monnieri by wild type strains of Agrobacterium rhizogenes stimulates production of bacopa saponins in transformed calli and plants. Plant Cell Rep 30:941-954. doi:10.1007/s00299-011$1035-9$

Moghadam AY, Piri K, Bahramnejad B, Ghiasvand T (2014) Dopamine production in hairy root cultures of Portulaca oleracea (Purslane) using Agrobacterium rhizogenes. J Agric Sci Technol 16:409-420

Nadkarni KM (1976) Indian material medical. Popular Prakashan 1(3):1119-1125

Nourozi E, Hosseini B, Hassani A (2016) Influences of various factors on hairy root induction in Agastache foeniculum (Pursh) Kuntze. Acta Agric Slov 107-1:45-54

Ono NN, Tian L (2011) The multiplicity of hairy root cultures: prolific possibilities. Plant Sci 180:439-446

Panda BM, Hazra S (2010) In vitro regeneration of Semecarpus anacardium $\mathrm{L}$. from axenic seedling derived nodal explants. Trees Struct Funct 24:733-742

Park S-U, Facchini PJ (2000) Agrobacterium rhizogenes-mediated transformation of opium poppy, Papaver somniferum L., and California poppy, Eschscholzia californica Cham., root cultures. J Exp Bot 347:1005-1016

Pawlicki-Jullian N, Sedira M, Welander M (2002) The use of Agrobacterium rhizogenes transformed roots to obtain transgenic shoots of the apple rootstock Jork 9. Plant Cell Tissue Organ Cult 70:163-171

Peng CX, Gong JS, Zhang XF, Zhang M, Zheng SQ (2008) Production of gastrodin through biotransformation of $p$-hydroxybenzyl alcohol using hairy root cultures of Datura tatula L. Afr J Biotechnol 7(3):211-216 
Rahnama H, Hasanloo T, Shams MR, Sepehrifar R (2008) Silymarin production by hairy root culture of Silybum marianum (L.) Gaertn. Irn. J Biotechnol 6(2):113-118

Rajkumar D, Murugesan R (2014) Hairy root induction of Psoralea corylifolia for enhanced production of antifungal compound against red rots pathogen Colletotrichum falcatum. Afr J Agric Res 9(8):755-765. doi:10.5897/AJAR2013.7520

Raut AKA, Sawant NS, Badre AS, Amonkar AJ, Vaidya ADB (2007) Bhallatak (Semecarpus anacardium Linn.) —a review. Indian J Trad Knowl 6(4):653-659

Romero FR, Delate K, Kraus GA, Solco AK, Murphy PA, Hannapel DJ (2009) Alkamide production from hairy root cultures of Echinacea. In Vitro Cell Dev Biol Plant 45(5):599-609. doi:10. 1007/s11627-008-9187-1

Rostampour S, Sohi SH, Jourabchi E, Ansari E (2009) Influence of Agrobacterium rhizogenes on induction of hairy roots and benzylisoquinoline alkaloids production in Persian poppy ( $\mathrm{Pa}$ paver bracteatum Lindl.): preliminary report. World J Microbiol Biotechnol 25:1807-1814

Samadi A, Carapetian J, Heidari R, Jafari M, Gorttapeh AH (2012) Hairy root induction in Linum mucronatum ssp mucronatum, an anti-tumor lignans producing plant. Not Bot Horti Agrobot 40(1):125-131

Sambrook J, Fritsch EF, Manitais T (1998) Molecular cloning a laboratory manual. Cold Spring Harbour Laboratory Press, Cold Spring Harbour

Saxena G, Banerjee S, Rahman L, Verma PC, Mallavarapu GR, Kumar S (2007) Rose-scented geranium (Pelargonium sp.) generated by Agrobacterium rhizogenes mediated Ri-insertion for improved essential oil quality. Plant Cell Tissue Organ Cult 90:215-223. doi:10.1007/s11240-007-9261-0

Schmidt JF, Moore MD, Pelcher LE, Covello PS (2007) High efficiency Agrobacterium rhizogenes mediated transformation of Saponaria vaccaria L. (Caryophyllaceae) using fluorescence selection. Plant Cell Rep 26:1547-1559

Setamam NM, Sidik NJ, Rahman ZA, Zain CRCM (2014) Induction of hairy roots by various strains of Agrobacterium rhizogenes in different types of Capsicum species explants. BMC Res Notes $7: 414-421$

Sevon N, Oksman C, Kirsi M (2002) Agrobacterium rhizogenes mediated transformation: root cultures as a source of alkaloids. Planta Med 68:859-868

Shi HP, Kintzios S (2003) Genetic transformation of Pueraria phaseoloides with Agrobacterium rhizogenes. Plant Cell Rep 21:1103-1107

Thwe A, Valan Arasu M, Li X, Park CH, Kim SJ, Al-Dhabi NA, Park SU (2016) Effect of different Agrobacterium rhizogenes strains on hairy root induction and phenylpropanoid biosynthesis in tartary buckwheat (Fagopyrum tataricum Gaertn). Front Microbiol 7:318. doi:10.3389/fmicb.2016.00318

Zhou M, Zhu Z, Shao J, Tang Y, Wu Y (2011) Production and metabolic engineering of bioactive substances in plant hairy root culture. Appl Microbiol Biotechnol 90:1229-1239. doi:10.1007/ s00253-011-3228-0 